دراسة حديثة لانكاز العينات النسيجية الرخوة

$$
\text { فرع التشريح والأنسجة - كلية الطب البيطري - جامعة بغداد الحسني }
$$

\begin{abstract}
الخلاصة
تمثل هذه الدراسة طريقة جديدة لانكاز العينات النسيجية المعروفة والمعمول بها في المختبرات المبهة

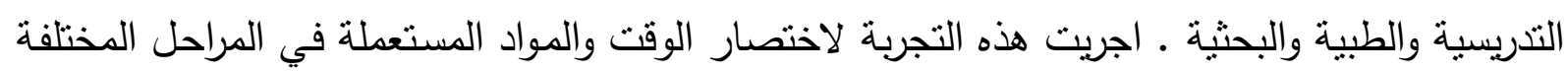

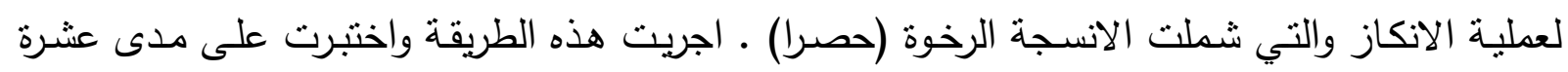

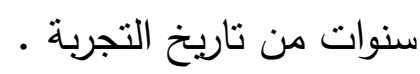

\title{
New study dehydration of soft histological specimens
}

\author{
Baha' F. Al-Hussany \\ Department of Anatomy and Histology, College of Veterinary Medicine, \\ University of Baghdad
}

\section{Summary}

This study represent a new process for dehydration of the histological specimen that knowledge and used in the laboratory study. Technical and medical research will be set up a completely great scientific and to addition of this to make an experiment, to a shortness the time and the material cost that is used in the different stage of dehydration and these for the soft tissue ( only ).

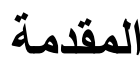

تعتبر عملية انكاز العينات النسيجية الرخوة بالكحولات المختلفة من الطرق القديمة والتي استمرت لعدة

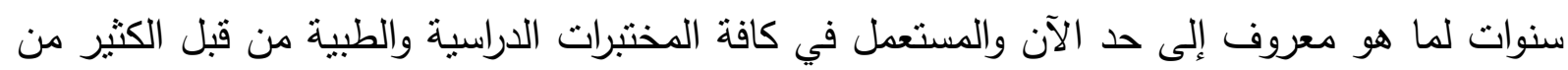
الباحثين ، فقد ذكر العديد من الباحثين حول عملية انكاز العينات باستعمال مواد كيميائية مختلفة (1 ،

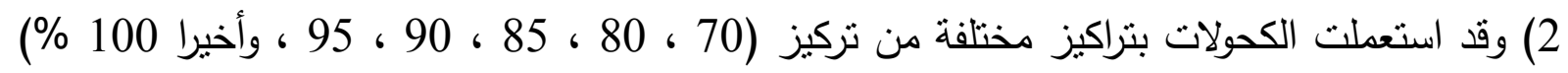
وكان الهدف من ذلك هو لإجراء عملية انكازالماء والمادة المثتبة الموجودة داخل الخلايا والأنسجة وإبداله

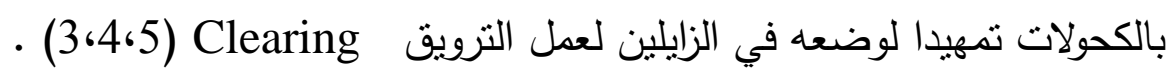




\section{المواد وطرائق العمل}

أخذت عينات بحجم 1- 2 سم3 من عضلة القلب والرئة والغدد اللعابية وبعد تثبيتها بالفورمالين

وتم غسلها ووضعها في أنايبب اختبار Test tube خاصة بجهاز الطرد المركزي أن تلف بالورق الترشيح Filter paper توضع هذه الأنابيب في الجهاز لمدة 25 دقيقة وبسرعة 3 آلاف

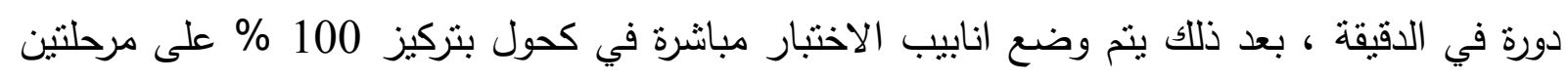

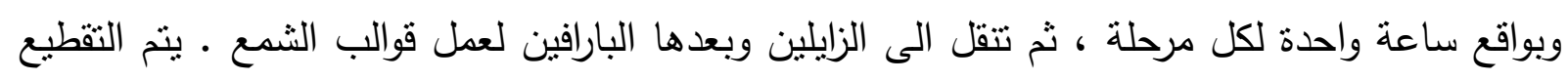

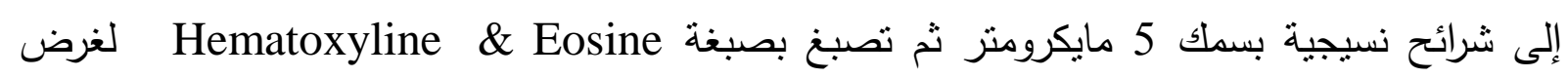

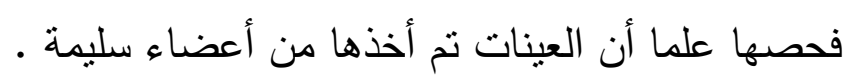

\section{النتائج}

اظهر الفحص النسجي للشرائح المأخوذة من عضلة القلب Heart والبنكرياس Pancreas كفاءة الطريقة الجديدة المستخدمة حيث حافظت الثرائح النسجية على جودنها

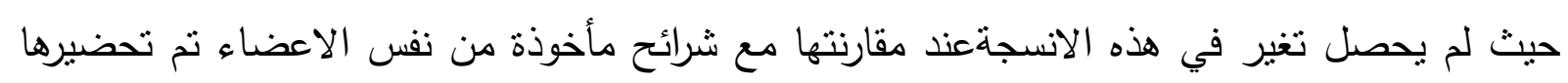

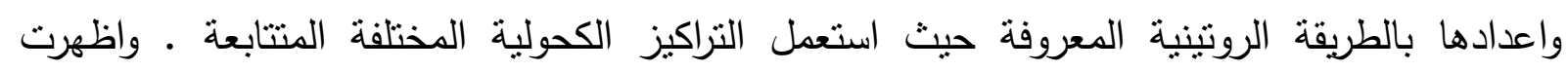

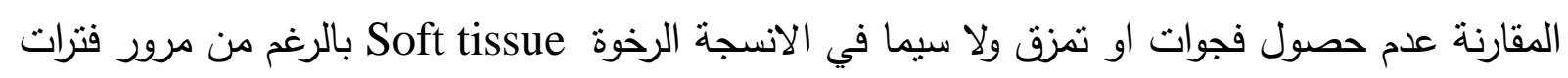
زمنية طويلة ، كما ان الخلايا ظهرت ذات شكل طبيعي وكذلك التراكيب النسيجية الاخرى . الفحص النسجي للشرائح كان على شكل تتابعي والذي تمنل بالآتي :

$$
\begin{aligned}
& \text { 1- نم فحص الثرائح بعد } 3 \text { اثشهر - }
\end{aligned}
$$

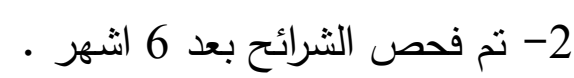

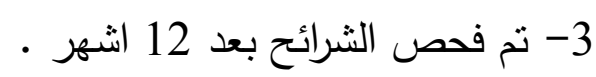

$$
\begin{aligned}
& \text { 4- نم فحص الثرائح بعد } 3 \text { سنوات . } \\
& \text { 5- تم فحص الثرائح بعد } 6 \text { سنوات . } \\
& \text { 6- نم فحص الثرائح بعد } 10 \text { سنوات . }
\end{aligned}
$$

وتظهر الصور المرفقة (1، 2 ، 3) توضيحا لهذه العملية والتي نم تصويرها بعد مرور عشر سنوات 


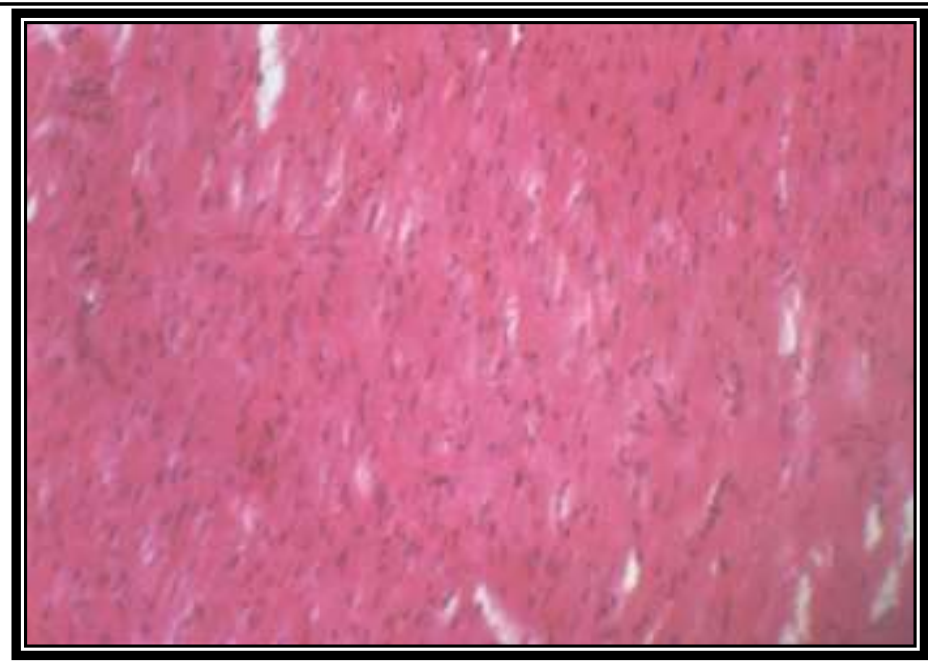

صورة رقم (1) : مقطع في عضلة القلب بعد مرور عشر

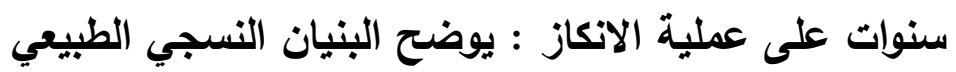
أي تغيير وعدم حدوث فيه . صبغة الهارس - هيماتوكسلين 264 X و الايوسين · قوة التكبير

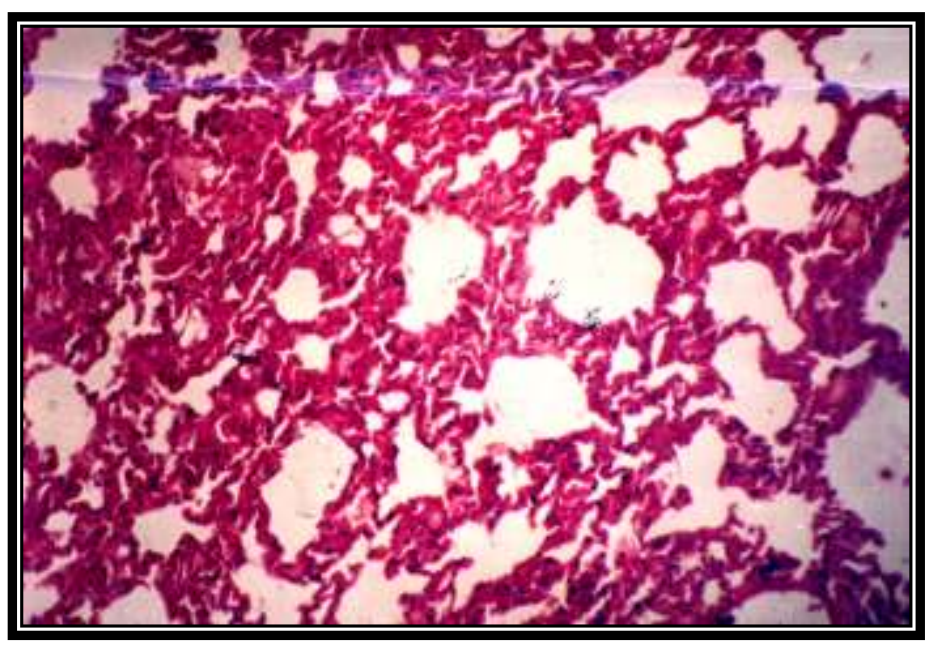

صورة رقم (2) : مقطع في الرئة بعد مرور عشر سنوات

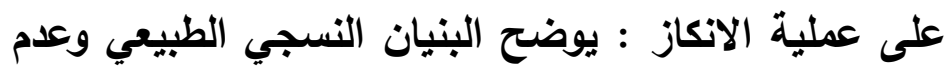

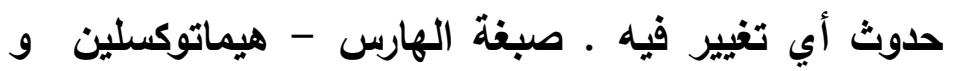

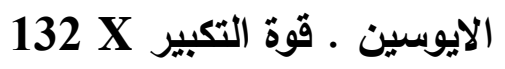




\section{المجلة الطبية البيطرية العراقية ، المجلد 29 ، العدد 2 ، السنة 2005}

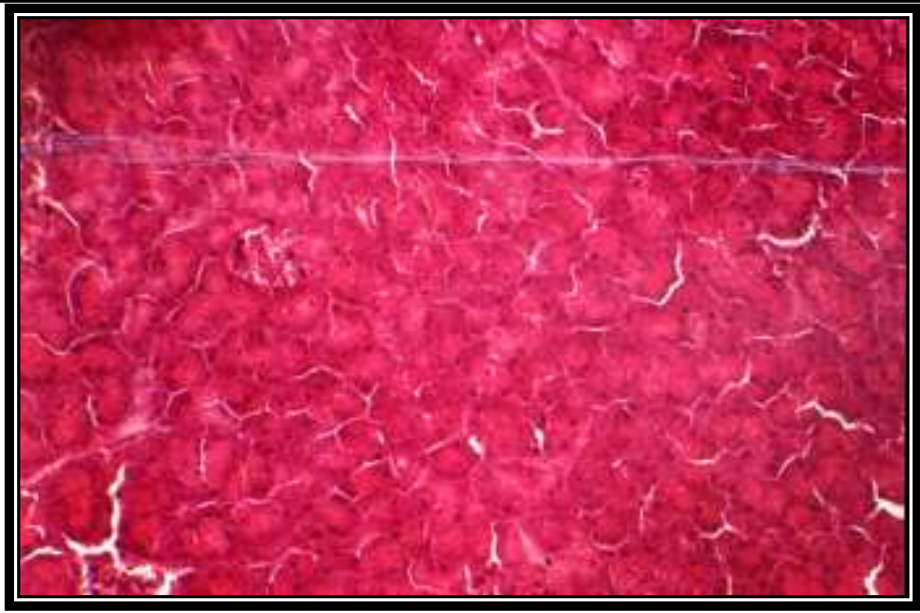

صورة رقم (3) : مقطع في البنكرياس بعد مرور عشر

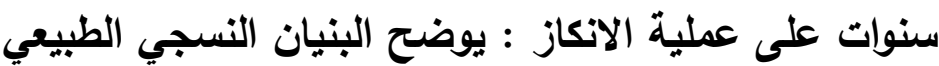

وعدم حدوث أي تغيير فيه ـ صبغة الهارس - هيماتوكسلين

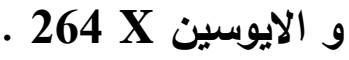

\section{المناقشة}

ان عملية تحضير الثرائح النسجية بالطرق الروتينية المعروفة والمستعملة حاليا اظهرت كفاءة

جيدة والتي تعتبر فيها عملية الانكاز بالكحولات ذات التراكيز المختلفة احدى خطواتها الرئيسية و

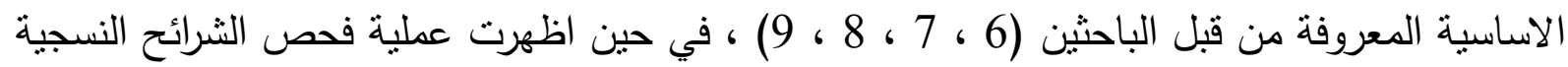
المأخوذة من العينات التي تم انكازها بالطريقة المستخدمة الجديدة ومقارنتها مع الثرائح النسجية السابقة عدم وجود أي اختلاف في شكل الخلابا والانسجة عدا ان الطريقة الجديدة تمتل اختصار كبير في الفترة الزمنية لعمل الثرائح النسجية وتقليل الكلفة المادية لها وكذلك كلفة استعمال المواد الكيمياوية المستعملة ، أي اختصار وقلة في الجهد الزمني والكلفة المادية ـ ان الفكرة من اخذ العينات من عضلة القلب والرئة و

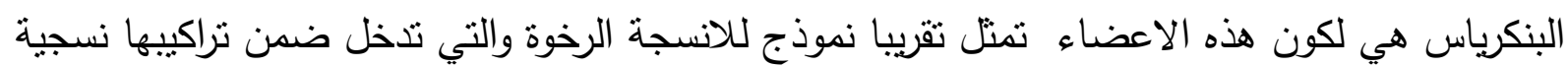

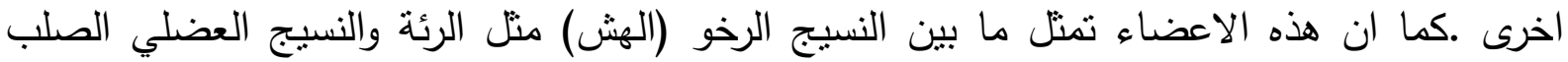

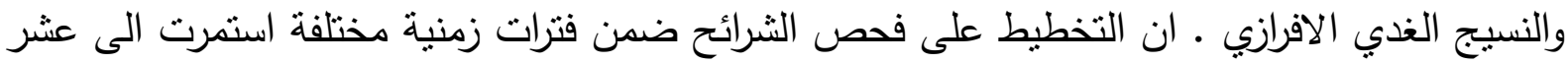

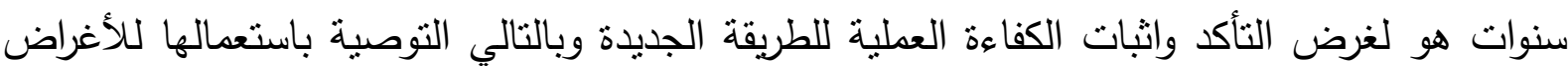

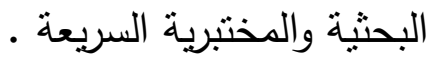




\section{References}

1. Kozolloff , Ph. D. (1968) : Practical microtechnique by the LateAlbert, E . Galigher \& Engene .

2. Luna , L . G . (1968) : Manual of histological staining method of the Armed Forces Institute of pathology . 3rd ed. Mc Graw- hill book Co ., New York .

3. Gurr , E . (1953). A practical manual of medical \& biological staining technique . Interscience publishers, INC. New York.

4. Clayclon, E. (1962) : Practical section cutting \& staining J \& A . Churchill Ltd .

5. Cook ,H. C. (1974) : Manual of histological demonstration technique Butterworth's \& Co (publishers) Ltd .

6. Gray , P. (1964) : Handbook of basic microtechnique , 3rd ed.Mc Graw Hill book company .

7. Purvis , M. J., Collier, D.C. \& Walls, D. (1966) : Laboratory technique in botany, 2nd ed. , London Butterworth's .

8. Durry , R. A. B. \& Wallington, E. A. (1967) : Carleton's histological technique, 4 th ed.

9. Junqueira L. C. (1977) : Basic histology . Lang medical publication , Los Atlos , California . 